Utjecaj sustava sjetve na prinos zrna kukuruza različitih FAO grupa

Impact of sowing system on maize grain yield of different FAO groups

Banaj, A, Banaj, Đ., Tadić, V., Petrović, D., Stipešević, B.

Poljoprivreda/Agriculture

ISSN: 1848-8080 (Online)

ISSN: 1330-7142 (Print)

http://dx.doi.org/10.18047/poljo.25.2.9

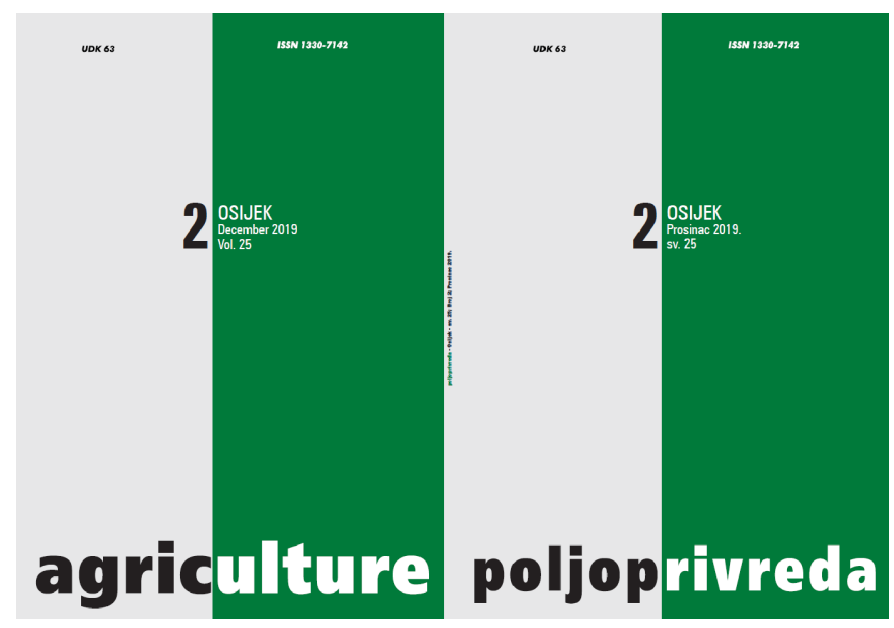

Fakultet agrobiotehničkih znanosti Osijek, Poljoprivredni institut Osijek

Faculty of Agrobiotechnical Sciences Osijek, Agricultural Institute Osijek 
$>$ ISSN $1330-7142$

$U D K=631.53 .04: 633.15$

DOI: $10.18047 /$ poljo.25.2.9

\title{
UTJECAJ SUSTAVA SJETVE NA PRINOS ZRNA KUKURUZA RAZLIČITIH FAO GRUPA
}

Banaj, A., Banaj, Đ., Tadić, V., Petrović, D., Stipešević, B.

Original scientific paper

Izvorni znanstveni članak

\begin{abstract}
SAŽETAK
U radu su prikazani rezultati prinosa zrna $\left(\mathrm{kg} \mathrm{ha}^{-1}\right)$ pri standardnoj sjetvi hibrida kukuruza i sjetvi u udvojene redove/sjetva u trake (engl. twin row sowing). Istraživanja su provedena od 2016. do 2018. godine na pokušalištu Fakulteta agrobiotehničkih znanosti, pokraj mjesta Tenja $\left(45^{\circ} 31^{\prime} 1,83^{\prime \prime}\right.$ s. z. š.; $18^{\circ} 46,37,5$ » i. z. d.). Na standardni sustav sjetve s razmakom redova od $70 \mathrm{~cm}$ sjetvom i sjetvom u udvojene redove $s$ razmakom od $22 \mathrm{~cm}$ posijani su hibridi $F A O$ grupa dozrijevanja: $H 1$ = FAO 290, H2 = FAO 380, H3 = FAO 410, H4 = FAO 450 i H5 = FAO 590. U standardnoj sjetvi hibrid H1 ostvario je prosječni prinos od $11.450 \mathrm{~kg} \mathrm{ha}^{-1}$, a sjetvom u udvojene redove $12.243 \mathrm{~kg} \mathrm{ha}^{-1}$ zrna, odnosno $3,77-9,66 \%$ više od standardne sjetve, ovisno o godini uzgoja. Hibrid $\mathrm{H} 2$ sjetvom u udvojene redove ostvario je veći prinos za 6,46 do 10,97\% u odnosu na standardnu sjetvu. Hibrid H3 u standardnoj sjetvi ostvario je prosječni prinos od $11.731 \mathrm{~kg} \mathrm{ha}^{-1}$, a kod sjetve u udvojene redove $12.763 \mathrm{~kg} \mathrm{ha}^{-1}$ (veći prinos zrna za 3,45-9,95\%). Najveća razlika u prinosa zrna između sustava sjetve utvrđena je 2018. godine kod hibrida H4, koji je ostvario veći prinos sjetvom u udvojene redove, za 11,72\%. Kod hibrida H5 utvrđene su najmanje razlike u prinosu zrna s obzirom na sustav sjetve, pa je u 2018. godina sjetva u trake ostvarila manji prinos za $0,59 \%$ s obzirom na standardnu sjetvu.
\end{abstract}

Ključne riječi: kukuruz, standardna sjetva, sjetva u udvojene redove/sjetva u trake, twin row sijaćica, prinos

\section{UVOD}

Sjetvom kukuruza u standardnom sustavu s razmakom redova od $70 \mathrm{~cm}$ može se zasijati 142 reda dužine $100 \mathrm{~m}$ na površini od 1 ha. Teorijsko iskorištenje vegetacijskoga prostora pri sklopu od 70.000 biljaka ha-1 iznosi $22,66 \%$ ili $323,65 \mathrm{~cm}^{2}$ po biljci. Sjetvom kukuruza u trake s razmakom udvojenih redova od $22 \mathrm{~cm}$ može se posijati 284 reda dužine $100 \mathrm{~m}$ na površini od 1 ha. Jednostavnim izračunom dobiva se rezultat iskorištenja vegetacijskoga prostora od $49,23 \%$ ili $703 \mathrm{~cm}^{2}$ po zasijanoj biljci, što predstavlja povećanje od $217,25 \%$ u odnosu na sjetvu u standardnome sustavu.

Rezultati istraživanja sjetve kukuruza u trake tijekom vegetacijske 2015. i 2016. godine na 25 lokaliteta u RH pokazala su povećanje prinosa zrna od 10 do $20 \%$ u odnosu na standardnu sjetvu (Banaj i sur., 2017.a). U spomenutome istraživanju autori navode rezultate prinosa zrna za dva hibrida Pioneer. Hibrid P0023 ostvario je povećanje prinosa za $10,35 \%$, a hibrid $P 0412$ za $10,59 \%$ više u odnosu na standardnu sjetvu. Banaj i sur. (2018.b) navode da je sjetva u trake u istočnome dijelu Hrvatske (mjesto Klisa/Osijek) ostvarila veće prinose zrna nego standardna sjetva. Navode da je hibrid Pioneer P9911 ostvario veći prinos za 2,44\% (odnosno $313 \mathrm{~kg} \mathrm{ha}^{-1}$ ) u odnosu na standardnu sjetvu. Povećanjem sklopa na 76.585 biljaka ha-1 sa sjetvom u trake ostvaren je prinos zrna od $13.879 \mathrm{~kg} \mathrm{ha}^{-1}$ ili $7,09 \%$ više u odnosu na standardnu sjetvu. Tadić i sur. (2017.) navode rezultate prinosa zrna pri standardnoj i sjetvu u udvojene redove za hibride ZP 488 i ZP 560 (Zemun polje) posijanih u okolici Osijeka. Hibrid ZP 488 ostvario je sjetvom u trake prinos veći za $6,48 \%$ u odnosu na standardni način

\footnotetext{
Anamarija Banaj, mag. ing. agr., prof. dr. sc. Đuro Banaj, doc. dr. sc. Vjekoslav Tadić, dr. sc. Davor Petrović, viši stručni suradnik, prof. dr. sc. Bojan Stipešević (bojan.stipesevic@fazos.hr) - Sveučilište Josipa Jurja Strossmayera u Osijeku, Fakultet agrobiotehničkih znanosti Osijek, Vladimira Preloga 1, 31000 Osijek, Hrvatska
} 
sjetve. Kod hibrida ZP 560 zabilježeno je nešto manje povećanje prinosa sjetvom u trake od $2,44 \%$. Jurković i sur. (2017.) navode rezultate prinosa zrna pri sjetvi dvaju hibrida (Pioneer P0412 i BC 525) u standardnoj sjetvi i sjetvi u trake na lokaciji bosanske posavine (Odžak). Sjetva u trake kod hibrida P0412 ostvarila je veći prinos za $5,53 \%$, a kod hibrida $B C 525$ za $13,95 \%$ više u odnosu na standardnu sjetvu. Banaj i sur. (2018.) navode rezultate prinosa zrna pri sjetvi hibrida $P 0023$ i $P 0412$ u standardnoj sjetvi i sjetvi u trake na lokaciji Đelekovca (OPG Jasne Puhar). Prinos zrna hibrida P0023 u standardnoj sjetvi iznosio je $12.882 \mathrm{~kg} \mathrm{ha}^{-1}$, a sjetvom u trake iznosio je $13.477 \mathrm{~kg} \mathrm{ha}^{-1}$, ili 4,62\% više u odnosu na standardnu sjetvu. Prinos hibrida P0412 iznosio je $12.605 \mathrm{~kg} \mathrm{ha}^{-1} \mathrm{u}$ standardnoj sjetvi, a sjetvom u trake iznosio je $13.339 \mathrm{~kg} \mathrm{ha}^{-1}$, ili $5,83 \%$ više u odnosu na standardnu sjetvu. Banaj i sur. (2018.a) navode rezultate prinosa zrna pri standardnoj sjetvi i sjetvi u trake na lokaciji Lužani (Brodsko-posavska županija). Sjetvom hibrida DKC 4555 i hibrida Chapalu RWA u oba slučaja sjetva u trake ostvarila je veći prinos zrna $(12,78 \%$ za DKC 4555 i 8,76\% za Chapalu RWA). Jurković i sur. (2018.) navode rezultate prinosa zrna kukuruza zasijanih u standardnoj sjetvi i sjetvi u trake na lokaciji OPG-a Jović (Prud/Odžak/BiH). U istraživanju autori navode da su hibridi OS 403 i OS 378 zasijani u trake sjetvi ostvarili veći prinos za 3,56\% te 7,66\% u odnosu na standardnu sjetvu. Banaj i sur. (2019.) navode da su hibridi Chapalu RWA (FAO 350) i Ferarixx RWA (FAO 360) sa sjetvom u trake na pokušalištu Fakulteta agrobiotehničkih znanosti iz Osijeka (Klisa) ostvarili veće prinose zrna za 5,59\% i $5,61 \%$ u odnosu na standardnu sjetvu. Povećanjem sjetvenoga sklopa hibrida Ferarixx na 88.040 biljaka ha ${ }^{-1}$ prinos zrna također se povećao $7,79 \%$ u odnosu na standardnu sjetvu.

Veći dio autora navodi slične rezultate, koji potvrđuju postojanje statistički značajnoga povećanja prinosa zrna kukuruza u sjetvi u udvojene redove u odnosu na standardnu sjetvu (Gutiérrez López i sur. 2014.; Küper 2014.). Također nisu statistički potvrdili da je veličina sklopa (biljaka ha-1) djelovala na ostvarenje prinosa ni kod jednog načina sjetve. Kod primjene sjetve u trake kod istoga sklopa biljaka, nisu zabilježene statistički značajne razlike u visini prinosu u odnosu na standardnu sjetvu (30 inča) u državama Alabama, lowa, Missouri i Nebraska (Elmore i Abendroth, 2007.; Nelson i Smoot,
2009.; Balkcom i sur., 2011.; Robles i sur., 2012.). Autori Roth i sur. (2002.) u svojim istraživanjima nisu utvrdili postojanje statistički značajnih razlika u visini prinosa između kukuruza sijanoga u standardnoj sjetvi i sjetvi u trake.

Ovim istraživanjem želi se provjeriti utjecaj različitoga prostornog rasporeda istoga broja biljaka kukuruza po površini na komponente prinosa zrna i sam urod, a za veći raspon FAO grupa dozrijevanja hibrida kukuruza, te tako utvrditi optimalne parametre nužne za primjenu ove tehnologije u široj proizvodnji.

\section{MATERIJAL I METODE}

Istraživanje je obavljeno od 2016. do 2018. godine na pokušalištu Fakulteta agrobiotehničkih znanosti Osijek - lokacija Klisa/Osječko-baranjska županija $\left(45^{\circ} 31^{\prime} 1,83^{\prime \prime}\right.$ s. z. š. $/ 18^{\circ} 46,37,5 »$ i. z. d. - k. 0 . Tenja; č. 1308 i 1309). Na standardni sustav sjetve s razmakom redova od 70 $\mathrm{cm}$ i sjetvom u udvojene redove s razmakom od $22 \mathrm{~cm}$ posijano je pet hibrida različitih FAO grupa (H1: FAO 290, H2: FAO 380, H3: FAO 410, H4: FAO 450 i H5: FAO 590) $\mathrm{s}$ istim ciljanim sklopom od 70.000 biljaka ha ${ }^{-1}$. Za standardnu sjetvu korištena je sijaćica PSK 4 OLT, dok je za sjetvu u trake korištena sijaćica MaterMacc Twin Row-2. Sjetve su obavljene u drugoj dekadi travnja, a berbe u prvoj dekadi listopada - ručno po dva unutarnja reda duljine $20 \mathrm{~m}$ u četiri ponavljanja. Iz FAO-ve grupe 200 zasijan je hibrid $H 1$, koji je namijenjen prvenstveno proizvodnji zrna. Hibrid $H 2$ odlikuje izrazito visok i stabilan prinos, dok hibrid $H 3$ pokazuje izuzetno visoku adaptabilnost na različite tipove tala te visoku tolerantnost na stresne uvjete proizvodnje. Hibrid $H 4$ vrlo dobro otpušta vlagu iz zrna, dok je hibrid $H 5$ namijenjen prvenstveno proizvodnji silaže, odnosno proizvodnji zrna na istočnijim dijelovima RH. Na Slici 1 prikazana je shema postavljenih sjetvenih sekcija pri standardnoj sjetvi (sijaćica PSK 4 OLT) i sjetvi u trake (sijaćica MaterMacc Twin Row-2), gdje je vidljivo da se sjetva izvodi u $22 \mathrm{~cm}$ razmaknute dvostruke redove, a treba naglasiti da je sjetveni mehanizam podešen tako da se sjeme polaže u tlo u sredinu između dva sjemena susjednoga reda, tako da se dobije tzv. "cik-cak" uzorak rasporeda sjemena te kasnije biljaka. Na ovaj način svaka biljka ima za razvoj korijena najveći mogući prostor do susjednih biljaka. 

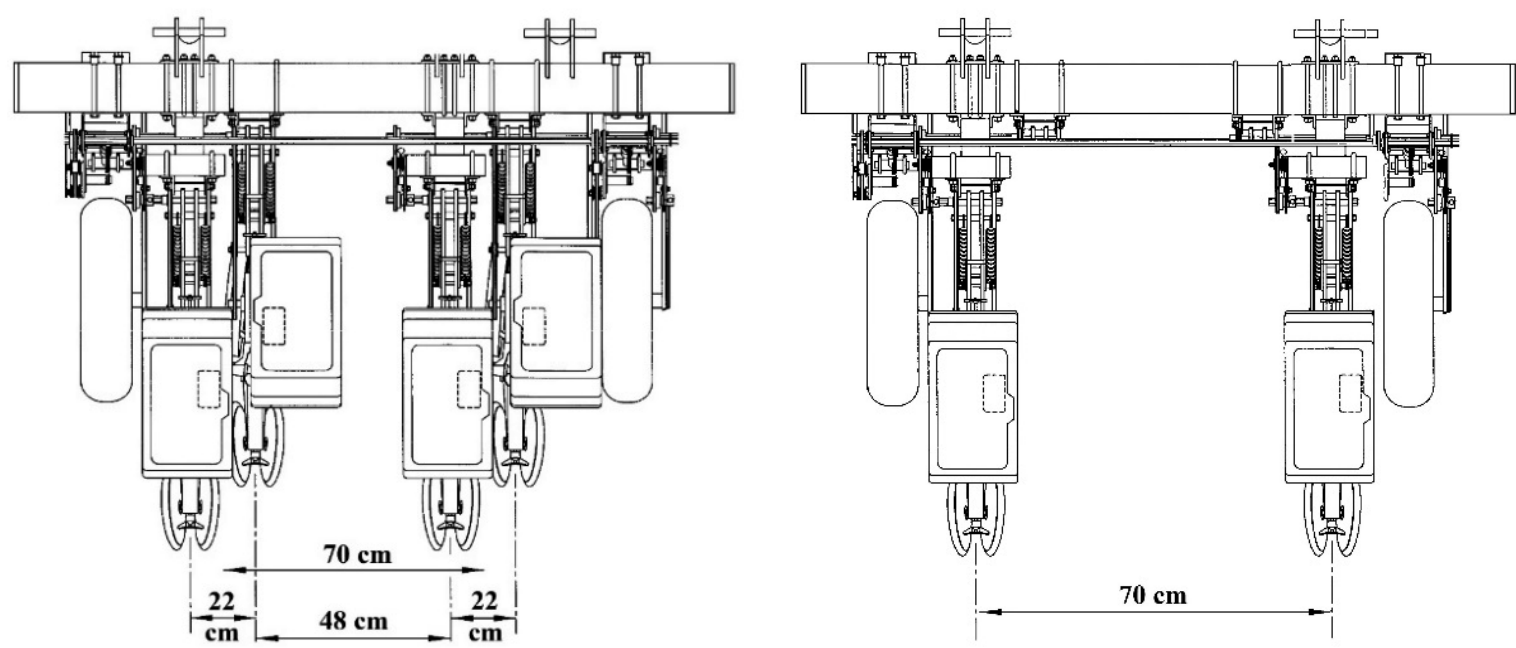

Slika 1. Razmak redova u sjetvi sijaćicom MaterMacc Twin Row-2 i sijaćicom PSK 4 OLT Figure 1. Row spacing obtained with MaterMacc Twin Row-2 and PSK 4 OLT sowing machine

Na Slici 2 prikazan je kukuruz posijan u trake s $22 \mathrm{~cm}$ razmaka između udvojenih redova i posijan u standardnome sustavu sa $70 \mathrm{~cm}$ razmaka između redova.

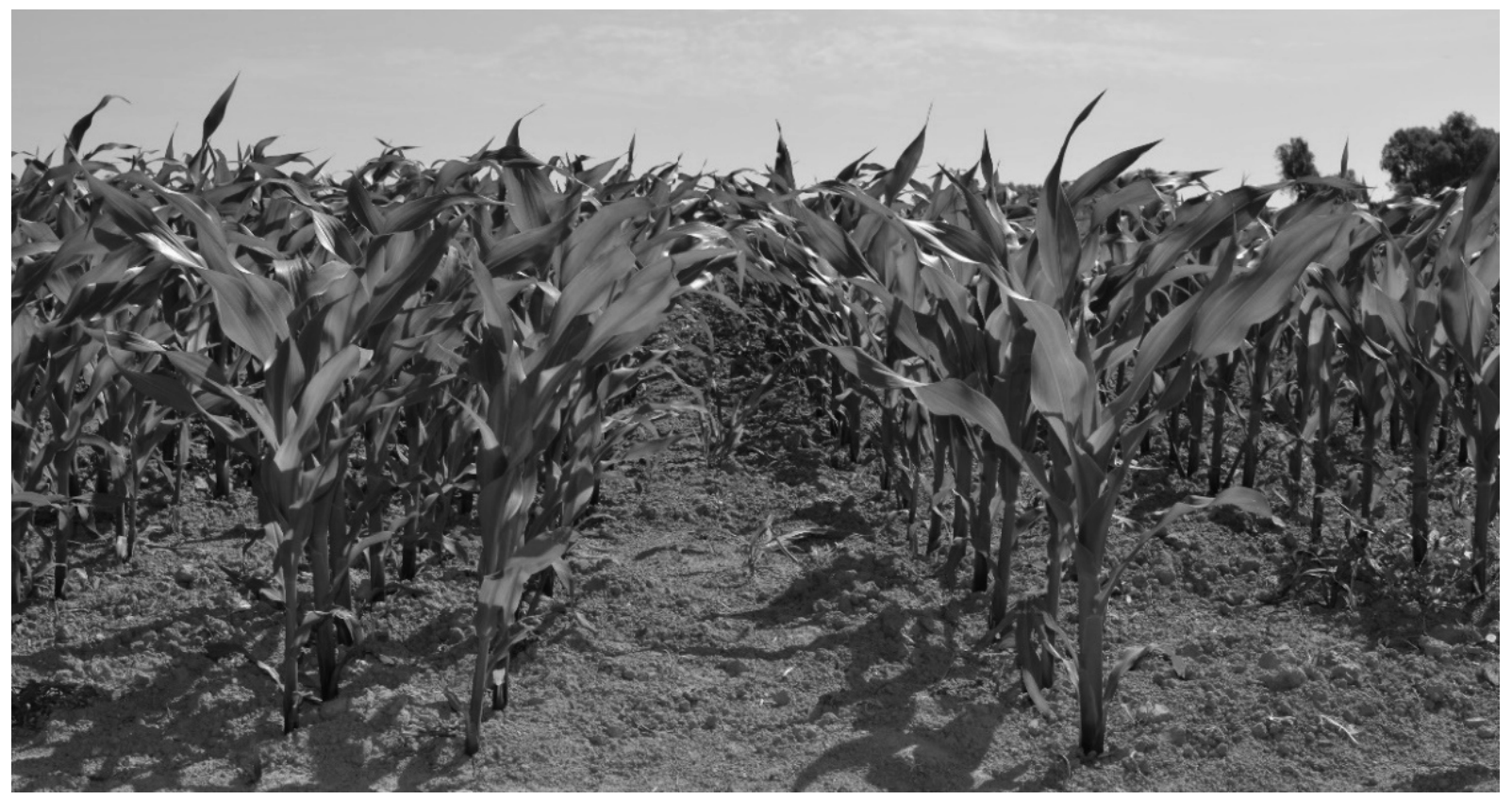

Slika 2. Sjetva kukuruza u trake (lijevo) i standardna sjetva (desno)

Figure 2. Twin row maize sowing (left) and standard sowing (right)

Statistička obrada podataka obavljena je paketom SAS Enterprise Guide 7.1. Istraživanje je postavljeno kao trofaktorijelni pokus sa četiri ponavljanja, pri čemu je određena statistička značajnost (ANOVA) za glavna svojstva istraživanja: sklop biljaka ha $^{-1}$, masa zrna po klipu i prinos zrna. Nakon analize varijance ispitana je statistički značajna razlika unutar vegetacijske godine, hibrida i sustava sjetve za navedena glavna svojstva istraživanja. Statistička značajnost svih svojstva određena je na razini $\alpha=0,05$. Uvjeti proizvodnje kukuruza u istraživanim godinama na pokušalištu Klisa prikazani su u sljedećim tablicama. U Tablici 1 prikazane su srednje mjesečne vrijednosti temperature zraka i ukupne količine oborina, a u Tablici 2 prikazane su ukupne vrijednosti sunčanih sati i relativne vlažnosti zraka. 
Tablica 1. Srednje mjesečne temperature zraka $\left({ }^{\circ} \mathrm{C}\right)$ i ukupne mjesečne količine oborina $(\mathrm{mm})$ - meteorološka postaja Klisa (Aerodrom)

Table 1. Mean air temperature $\left({ }^{\circ} \mathrm{C}\right.$ ) and total monthly precipitation $(\mathrm{mm})$ - meteorological station Klisa (Airport)

\begin{tabular}{|c|c|c|c|c|c|c|c|c|}
\hline \multirow{3}{*}{$\begin{array}{l}\text { Mjesec } \\
\text { Month }\end{array}$} & \multicolumn{8}{|c|}{ Godina / Year } \\
\hline & \multicolumn{2}{|c|}{2016.} & \multicolumn{2}{|c|}{2017.} & \multicolumn{2}{|c|}{2018.} & \multicolumn{2}{|c|}{ 1981.-2015. } \\
\hline & $T_{z}$ & 0 & $T_{z}$ & 0 & $T_{z}$ & 0 & $T_{z}$ & 0 \\
\hline I. & 0,9 & 70,6 & $-5,1$ & 36,9 & 4,2 & 59,1 & $-0,1$ & 43,9 \\
\hline II. & 6,7 & 76,0 & 3,8 & 52,1 & 0,9 & 70,9 & 1,2 & 42,5 \\
\hline III. & 7,7 & 58,0 & 10,0 & 55,7 & 4,6 & 71,9 & 6,4 & 49,8 \\
\hline IV. & 13,6 & 38,1 & 11,6 & 54,8 & 17,0 & 25,1 & 12,0 & 48,4 \\
\hline V. & 17,1 & 39,6 & 18,3 & 50,5 & 20,6 & 77,6 & 17,2 & 77,9 \\
\hline VI. & 21,7 & 164,8 & 23,4 & 35,7 & 21,7 & 102,9 & 20,4 & 77,9 \\
\hline VII. & 23,2 & 114,2 & 23,9 & 60,1 & 22,5 & 89,2 & 22,5 & 58,2 \\
\hline VIII. & 21,1 & 48,7 & 24,2 & 24,0 & 24,4 & 45,6 & 21,7 & 60,1 \\
\hline IX. & 18,5 & 37,6 & 16,5 & 65,6 & 18,3 & 106,1 & 17,1 & 52,6 \\
\hline $\mathrm{X}$. & 10,6 & 68,0 & 12,4 & 55,7 & 14,4 & 13,7 & 11,6 & 56,5 \\
\hline XI. & 6,1 & 54,8 & 6,9 & 37,3 & 7,6 & 31,9 & 5,9 & 50,5 \\
\hline XII. & 0,0 & 0,8 & 3,5 & 44,0 & 1,5 & 24,4 & 1,8 & 41,7 \\
\hline $\begin{array}{l}\text { Ukupno IV.-X. } \\
\text { Total IV-X }\end{array}$ & 18,0 & 511,0 & 18,6 & 346,4 & 19,8 & 460,2 & 17,5 & 431,6 \\
\hline $\begin{array}{l}\text { Ukupno I.-XII. } \\
\text { Total I-XII }\end{array}$ & 12,3 & 771,2 & 12,4 & 571,4 & 13,1 & 718,4 & 11,5 & 656,9 \\
\hline
\end{tabular}

Izvor: $D H M Z$ (2019.); $T_{z}$ - temperatura zraka $\left({ }^{\circ} \mathrm{C}\right) ; 0$ - oborine (mm); $I V .-X$ - vegetacija kukuruza

Source: CMHS (2019); $T_{Z}$ - air temperature $\left({ }^{\circ} \mathrm{C}\right)$; 0 - precipitation (mm); IV-X - maize vegetation

Tablica 2. Ukupne mjesečne vrijednosti sunčanih sati $(h)$ i relativne vlage zraka $(\%)$ - meteorološka postaja Klisa (Aerodrom)

Table 2. Total monthly values of sunshine (h) and relative air humidity (\%) - meteorological station Klisa (Airport)

\begin{tabular}{|l|c|c|c|c|c|c|c|c|}
\hline \multirow{2}{*}{$\begin{array}{l}\text { Mjesec } \\
\text { Month }\end{array}$} & \multicolumn{9}{|c|}{ Godina / Year } \\
\cline { 2 - 10 } & \multicolumn{2}{|c|}{2016.} & \multicolumn{2}{c|}{2017.} & \multicolumn{2}{c|}{2018.} & \multicolumn{2}{c|}{$1981 .-2015}$. \\
\cline { 2 - 10 } & $S_{s}$ & $R_{v}$ & $S_{s}$ & $R_{v}$ & $S_{s}$ & $R_{v}$ & $S_{s}$ & $R_{v}$ \\
\hline I. & 78,2 & 84 & 70 & 83 & 100,5 & 84 & 68,3 & 86 \\
\hline III. & 75,6 & 82 & 89,4 & 82 & 51,10 & 86 & 82,1 & 82 \\
\hline IV. & 127,8 & 78 & 172,1 & 69 & 83,4 & 81 & 158,1 & 74 \\
\hline V. & 185,6 & 69 & 162,0 & 66 & 242,4 & 62 & 207,6 & 69 \\
\hline VI. & 221,5 & 68 & 287,8 & 66 & 295,8 & 65 & 240,3 & 69 \\
\hline VII. & 219,5 & 71 & 308,2 & 61 & 198,1 & 73 & 267,0 & 69 \\
\hline VIII. & 294,5 & 69 & 344,5 & 61 & 234,9 & 73 & 300,6 & 66 \\
\hline IX. & 279,7 & 71 & 317,7 & 62 & 311,2 & 68 & 282,9 & 68 \\
\hline X. & 114,2 & 70 & 164,4 & 73 & 240,9 & 70 & 192,1 & 72 \\
\hline XI. & 93,6 & 82 & 81,9 & 83 & 110,9 & 80 & 96,6 & 84 \\
\hline XII. & 87,9 & 82 & 80,8 & 83 & 48,3 & 87 & 53,6 & 87 \\
\hline $\begin{array}{l}\text { Ukupno IV.-X. } \\
\text { Total IV-X }\end{array}$ & 1526,7 & 69,7 & 1771,9 & 64,8 & 1709,9 & 68,4 & 1642,4 & 70,0 \\
\hline $\begin{array}{l}\text { Ukupno I.-XII. } \\
\text { Total I-XII }\end{array}$ & 1989,8 & 75,5 & 2266,1 & 72,0 & 2104,1 & 75,0 & 2101,1 & 75,0 \\
\hline
\end{tabular}

Izvor: DHMZ (2019.), $S_{s}$ - ukupan broj sunčanih sati (h); $R_{v}$ - relativna vlažnost zraka (\%); IV.-X. - vegetacija kukuruza

Source: CMHS (2019), $S_{s}$ - total value of sunshine (h); $R_{v}$ - relative air humidity (\%); IV-X - maize vegetation 

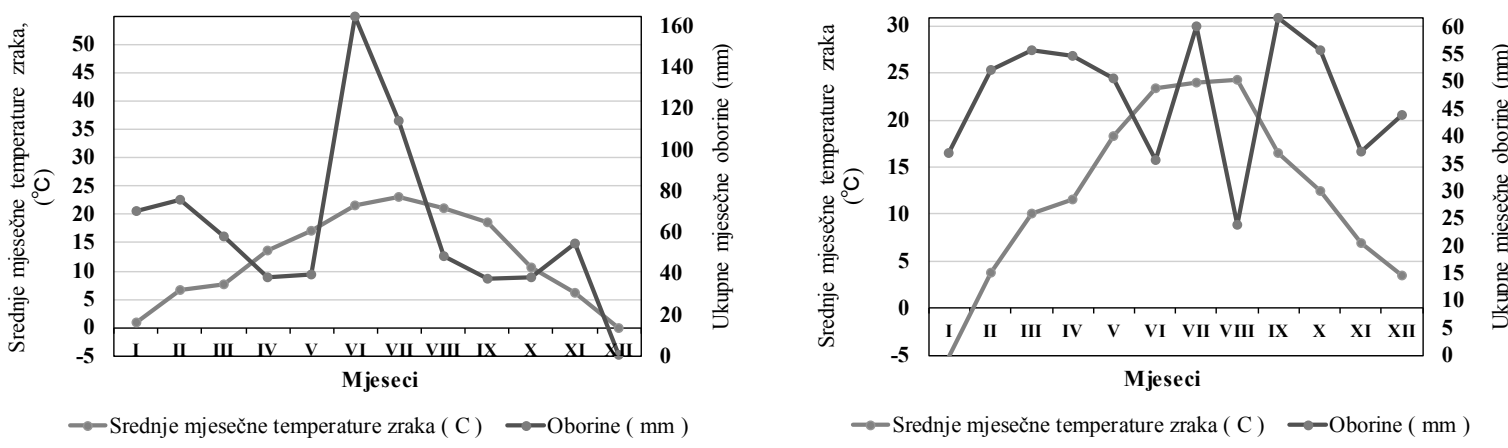

Grafikon 1. Klimadijagram prema Walteru za 2016. (lijevo) i 2017. god. (desno) - meteorološka postaja Klisa (Aerodrom)

Graph 1. Climate diagram according to Walther method for 2016 (left) and 2017 (right) - meteorological station Klisa (Airport)
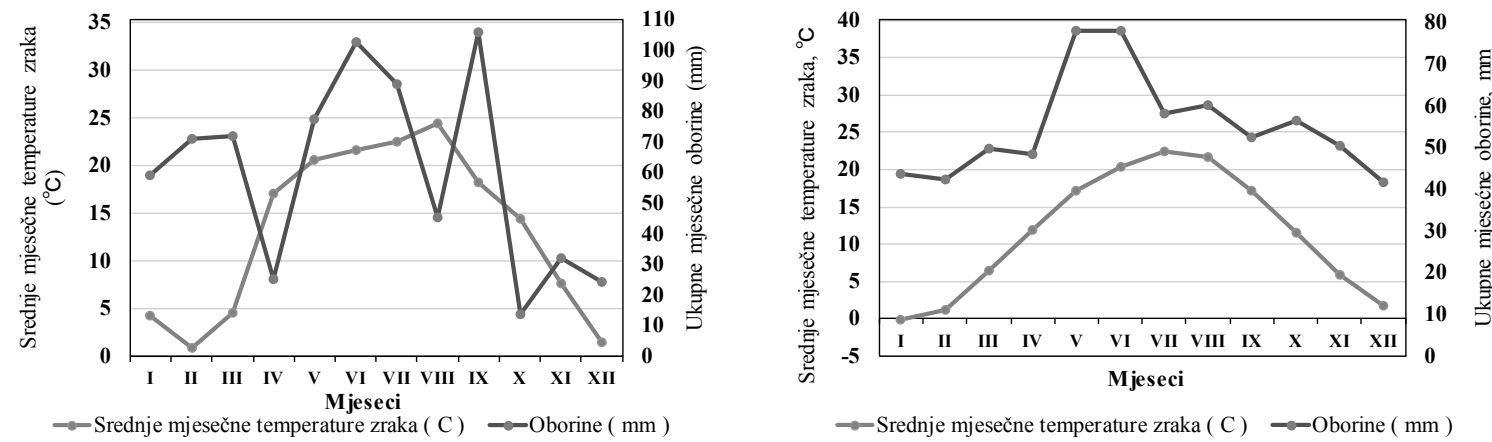

Grafikon 2. Klimadijagrami prema Walteru za 2018. godinu (lijevo) te za razdoblje od 1981. do 2015. godine (desno) - meteorološka postaja Klisa (Aerodrom)

Graph 2. Climate diagrams according to Walther method for 2018 (left) and period 1981-2015 (right) - meteorological station Klisa (Airport)

Na pokušališu Klisa prevladava eutrično smeđe tlo, koje pripada odjelu automorfnih tala, klasi kambičnih tala, sa sklopom profila P-C zbog antropogenizacije sklopa A-(B)v-C obradom tla. Tlo prema teksturi pripada u praškaste ilovače te je malo porozno, s osrednjim kapacitetom tla za vodu u oraničnome i podoraničnom horizontu. Reakcija tla je alkalna u svim horizontima, s dosta humoznim oraničnim slojem s umjerenom opskrbljenošću fosforom 15,58 $\mathrm{mg} / 100 \mathrm{~g}$ te umjerenom opskrbljenošću kalijem (Tablica 3). Neke pedomorfološke značajke korištenoga tla prikazane su u Tablici 3.

Tablica 3. Tip tla i njegova svojstva na području pokušališta Klisa

Table 3. Soil type and characteristics of soil on experimental field Klisa

\begin{tabular}{|c|c|c|c|c|c|}
\hline \multirow{2}{*}{$\begin{array}{l}\text { Lokacija } \\
\text { Location }\end{array}$} & \multirow{2}{*}{$\begin{array}{c}\text { Dubina } \\
\text { Depth } \\
\text { (cm) }\end{array}$} & \multicolumn{2}{|c|}{$p H$} & \multicolumn{2}{|r|}{ Humus } \\
\hline & & $\mathrm{H}_{2} \mathrm{O}$ & $\begin{array}{c}\text { Ocjena } \\
\text { Evaluation }\end{array}$ & $\%$ & $\begin{array}{c}\text { Ocjena } \\
\text { Evaluation }\end{array}$ \\
\hline Klisa (Osijek) & $0-30$ & 8,44 & $\begin{array}{l}\text { Alkalna } \\
\text { Alcaline }\end{array}$ & 3,71 & $\begin{array}{l}\text { Dosta humozno } \\
\text { Quite humorous }\end{array}$ \\
\hline \multicolumn{2}{|l|}{$\begin{array}{l}\text { Karbonati } \\
\text { Carbonates }\end{array}$} & \multicolumn{2}{|c|}{$A L-P_{2} O_{5}$} & \multicolumn{2}{|r|}{$A L-K_{2} \mathrm{O}$} \\
\hline$\%$ & $\begin{array}{c}\text { Ocjena } \\
\text { Evaluation }\end{array}$ & $\mathrm{mg} / 100 \mathrm{~g}$ & $\begin{array}{c}\text { Ocjena } \\
\text { Evaluation }\end{array}$ & $\mathrm{mg} / 100 \mathrm{~g}$ & $\begin{array}{c}\text { Ocjena } \\
\text { Evaluation }\end{array}$ \\
\hline 9,63 & $\begin{array}{l}\text { Srednje karbonatna } \\
\text { Medium carbonate }\end{array}$ & 15,58 & $\begin{array}{l}\text { Umjerena } \\
\text { Moderate }\end{array}$ & 24,29 & $\begin{array}{l}\text { Dobra } \\
\text { Good }\end{array}$ \\
\hline \multicolumn{5}{|c|}{ Tekstura tla / Soil texture } & \multirow{3}{*}{$\begin{array}{l}\text { Teksturna oznaka } \\
\text { Texture index }\end{array}$} \\
\hline $\begin{array}{l}\text { Glina } \\
\text { Clay }\end{array}$ & $\begin{array}{l}\text { Sitni prah } \\
\text { Fine silt }\end{array}$ & $\begin{array}{c}\text { Krupni prah } \\
\text { Coarse silt }\end{array}$ & $\begin{array}{l}\text { Sitni pijesak } \\
\text { Fine sand }\end{array}$ & $\begin{array}{l}\text { Krupni pijesak } \\
\text { Coarse sand }\end{array}$ & \\
\hline$<0,002 \mathrm{~mm}$ & $0,002-0,02 \mathrm{Mm}$ & $0,02-($ & $2 \mathrm{~mm}$ & $0,2-$ & \\
\hline $25,67 \%$ & $27,63 \%$ & $42,62 \%$ & $3,48 \%$ & $0,60 \%$ & $\begin{array}{c}\text { Praškasta ilovača } \\
\text { Silty loam }\end{array}$ \\
\hline
\end{tabular}




\section{REZULTATI I RASPRAVA}

Analizom varijance (Tablica 4) utvrđeno je da nema statistički značajnoga utjecaja vremenskih prilika (čimbenik godine), hibrida i sustava sjetve na sklop biljaka, što je i bilo očekivati jer su obje sijaćice podešene na isti broj posijanih zrna i dubinu sjetve. Osim dobro podešenih sijaćica (nema statističkih značajnosti u ostvarenome sklopu) signifikantan utjecaj na masu zrna po klipu ostvaruju sva tri glavna čimbenika (godina, sustav sjetve i hibrid). Slično je utvrđeno i s prinosom zrna, gdje također sva tri čimbenika ostvaruju signifikantan utjecaj.

Tablica 4. Analiza varijance za glavne čimbenike istraživanja

Table 4. Variance analysis for main properties of research

\begin{tabular}{|l|c|c|c|c|c|c|}
\hline \multirow{2}{*}{ ANOVA } & \multicolumn{2}{|c|}{$\begin{array}{c}\text { Sklop / Set of plants } \\
\left(\text { biljaka ha }^{-1} / \text { plants ha }^{-1}\right)\end{array}$} & \multicolumn{2}{c|}{$\begin{array}{c}\text { Masa zrna po klipu } \\
\text { Mass of grain per cob } \\
\left(\mathrm{g} \mathrm{klip}^{-1} / \mathrm{g} \mathrm{cob}^{-1}\right)\end{array}$} & \multicolumn{2}{|c|}{$\begin{array}{c}\text { Prinos zrna } \\
\text { Grain yield } \\
\left(\mathrm{kg} \mathrm{ha}^{-1}\right)\end{array}$} \\
\cline { 2 - 7 } & F-test & $p$ & $F$-test & $p$ & $F$-test & $P$ \\
\hline$A$ & $3,063^{\text {n.s. }}$ & 0,052 & $618,525^{*}$ & $<, 0001$ & $89,978^{*}$ & $<, 0001$ \\
\hline$B$ & $0,041^{\text {n.s. }}$ & 0,839 & $205,891^{*}$ & $<, 0001$ & $34,816^{*}$ & $<, 0001$ \\
\hline$C$ & $1,702^{\text {n.s. }}$ & 0,156 & $14,989^{*}$ & $<, 0001$ & $5,205^{*}$ & 0,001 \\
\hline$A B$ & $1,265^{\text {n.s. }}$ & 0,287 & $3,236^{*}$ & 0,044 & $1,537^{\text {n.s. }}$ & 0,221 \\
\hline$B C$ & $0,703^{\text {n.s. }}$ & 0,688 & $18,264^{*}$ & $<, 0001$ & $2,714^{*}$ & 0,010 \\
\hline$A B C$ & $0,427^{\text {n.s. }}$ & 0,789 & $5,566^{*}$ & $<, 0001$ & $1,570^{\text {n.s. }}$ & 0,189 \\
\hline
\end{tabular}

A - godina / year; B - sustav sjetve / sowing system; C - hibrid / hybrid

Tijekom proizvodnje kukuruza u 2016. godine hibrid $H 1$ ostvario je prosječan prinos od $11.375 \mathrm{~kg}$ $h^{-1}$, s prosječnom masom od $188,56 \mathrm{~g}$ po klipu. Sjetvom istoga hibrida u trake ostvaren je prinos od $11.821 \mathrm{~kg} \mathrm{ha}^{-1}$, ili svega $3,77 \%$ više u odnosu na standardni način sjetve. Najveća razlika od $10,97 \%$ u prinosu zabilježena je kod hibrida $\mathrm{H} 2$ sa sjetvom u trake (Tablica 5).

Tablica 5. Sklopovi biljaka kukuruza, masa zrna po klipu i ukupni urod zrna u 2016. godini sa standardnom sjetvom i sjetvom u trake

Table 5. Set of plants, grain weight per cob and grain yield in 2016 obtained with standard and twin row sowing

\begin{tabular}{|c|c|c|c|c|c|c|c|}
\hline \multirow{3}{*}{$\begin{array}{l}\text { Hibridi } \\
\text { Hybrid }\end{array}$} & \multicolumn{7}{|c|}{ Vegetacijska 2016. godina / Vegetation of 2016} \\
\hline & \multicolumn{2}{|c|}{$\begin{array}{l}\text { Sklop / Set of plants } \\
\left(\text { Biljaka ha }^{-1} / \text { plants ha }^{-1}\right)\end{array}$} & \multicolumn{2}{|c|}{$\begin{array}{l}\text { Masa zrna po klipu } \\
\text { Mass of grain per cob } \\
\left(\mathrm{g} \mathrm{klip}^{-1} / \mathrm{g} \mathrm{cob}^{-1}\right)\end{array}$} & \multicolumn{2}{|c|}{$\begin{array}{l}\text { Prinos zrna } \\
\text { Grain yield } \\
\left(\mathrm{kg} \mathrm{ha}^{-1}\right)\end{array}$} & \multirow{2}{*}{$\begin{array}{c}\text { Otklon uroda } \\
\text { Yield deviation } \\
(\%)\end{array}$} \\
\hline & $S T$ & $T R$ & ST & $T R$ & $S T$ & $T R$ & \\
\hline$H 1$ & 60350 & $61060^{\text {n.s. }}$ & 188,56 & $193,48^{\text {n.s. }}$ & 11375 & $11821^{\text {n.s. }}$ & 3,77 \\
\hline H2 & 63013 & $66030^{\text {n.s. }}$ & 194,61 & $208,61^{*}$ & 12262 & $13774^{*}$ & 10,97 \\
\hline$H 3$ & 62835 & $64610^{\text {n.s. }}$ & 196,54 & $211,98^{*}$ & 12340 & $13701^{*}$ & 9,93 \\
\hline$H 4$ & 62480 & $63190^{\text {n.s. }}$ & 194,99 & $209,83^{*}$ & 12193 & $13262^{\text {n.s. }}$ & 8,06 \\
\hline H5 & 63545 & $64255^{\text {n.s. }}$ & 206,98 & $212,06^{\text {n.s. }}$ & 13158 & $13632^{\text {n.s. }}$ & 3,47 \\
\hline
\end{tabular}

ST - standardna sjetva / standard sowing; TR - sjetva u trake; udvojene redove / twin row sowing

Prema Tablici 5 nije utvrđena statistički značajna razlika između sustava sjetve promatrajući sklop biljaka kod različitih hibrida u 2016. godini. Kod mase zrna po kipu, statistički značajna razlika sustava sjetve nije utvrđena kod hibrida $\mathrm{H} 5 \mathrm{i} H 1$. Veći prinos zrna sa sjetvom u trake ostvarili su hibridi $H 2$ i $H 3$ s obzirom na standardnu sjetvu. Slične rezultate potvrdili su autori Banaj i sur. (2017.b) pri sjetvi istih hibrida u istoj vegetacijskoj godini, ali na drugom lokalitetu. Autori navode da je hibrid $\mathrm{H} 2$ sa sjetvom u trake ostvario prinos od $13.712 \mathrm{~kg} \mathrm{ha}^{-1}$, tj. za 10,07\% više u odnosu na standardnu sjetvu. Međutim, kod hibrida $\mathrm{H3}$ na istoj lokaciji utvrđen je pad prinosa od $5,6 \%$ u odnosu na standardnu sjetvu $14.533 \mathrm{~kg} \mathrm{ha}^{-1}$. U 2017. godini najveća razlika u visini prinosa kod ispitivanih hibrida $\mathrm{s}$ obzirom na sustav sjetve ostvarena je kod hibrida $H 1$, od $9,66 \%$ u odnosu na standardnu sjetvu. Najmanja razlika od svega $0,31 \%$ ostvarena je kod hibrida $H 4$. Ostali hibridi ostvarili su veći prinos sa sjetvom u trake u odnosu na standardu sjetvu od 1,79 do 6,45\% (Tablica 6). Statistički veći prinos zrna sa sjetvom u trake ostvaren je samo sa hibridom H1. Postojanje statistički značajnoga povećanja prinosa zrna kukuruza u sjetvi u udvojene redove u odnosu na standardnu sjetvu potvrđuju i García Ramos i sur. (2014.), kao i Jócsák (2014.). 
Tablica 6. Sklopovi biljaka kukuruza, masa zrna po klipu i ukupni urod zrna u 2017. godini sa standardnom sjetvom i sjetvom u trake

Table 6. Set of plants, grain weight per cob and grain yield in 2017 obtained with standard and twin row sowing

\begin{tabular}{|c|c|c|c|c|c|c|c|}
\hline \multirow{3}{*}{$\begin{array}{l}\text { Hibridi } \\
\text { Hybrid }\end{array}$} & \multicolumn{7}{|c|}{ Vegetacijska 2017. godina / Vegetation of 2017} \\
\hline & \multicolumn{2}{|c|}{$\begin{array}{l}\text { Sklop / Set of plants } \\
\left(\text { Biljaka ha- } / \text { plants ha }{ }^{-1}\right)\end{array}$} & \multicolumn{2}{|c|}{$\begin{array}{l}\text { Masa zrna po klipu } \\
\text { Mass of grain per cob } \\
\left(\mathrm{g} \mathrm{klip}^{-1} / \mathrm{g} \mathrm{cob}^{-1}\right)\end{array}$} & \multicolumn{2}{|c|}{$\begin{array}{l}\text { Prinos zrna } \\
\text { Grain yield } \\
\left(\mathrm{kg} \mathrm{ha}^{-1}\right)\end{array}$} & \multirow{2}{*}{$\begin{array}{c}\text { Otklon uroda } \\
\text { Yield deviation }\end{array}$} \\
\hline & $S T$ & $T R$ & $S T$ & $T R$ & $S T$ & $T R$ & \\
\hline$H 1$ & 63900 & $61060^{\text {n.s. }}$ & 167,10 & $193,48^{*}$ & 10680 & $11821 *$ & 9,66 \\
\hline$H 2$ & 64255 & $63545^{\text {n.s. }}$ & 167,78 & $181,32^{*}$ & 10786 & $11532^{\text {n.s. }}$ & 6,46 \\
\hline H3 & 65498 & $66030^{\text {n.s. }}$ & 161,66 & $166,05^{\text {n.s. }}$ & 10580 & $10959^{\text {n.s. }}$ & 3,45 \\
\hline$H 4$ & 66208 & $65178^{\text {n.s. }}$ & 163,85 & $166,05^{\text {n.s. }}$ & 10848 & $10814^{\text {n.s. }}$ & $-0,31$ \\
\hline H5 & 66385 & $64610^{\text {n.s. }}$ & 164,99 & $172,82^{\text {n.s. }}$ & 10960 & $11160^{\text {n.s. }}$ & 1,79 \\
\hline
\end{tabular}

ST - standardna sjetva / standard sowing; TR - sjetva u trake; udvojene redove / twin row sowing

Iz Tablice 7 zamjećuje se da je hibrid $H 2$ ostvario prosječan prinos zrna od $12.335 \mathrm{~kg} \mathrm{ha}^{-1}$, s prosječnom masom zrna po klipu od 194,92 grama u standardnome načinu sjetve. Isti hibrid pri sjetvi u udvojene redove ostvario je prinos od $13.843 \mathrm{~kg} \mathrm{ha}^{-1}$ ili $10,89 \%$ više u odnosu na standardnu sjetvu. Statistički značajno veći prinos zrna sjetvom u trake s obzirom na standardnu sjetvu ostvarili su hibridi $H 2, H 3$ i $H 4$. Blandino i sur. (2013.) u svojim istraživanjima također potvrđuju veće prinose sjetvom u trake nego u standardnome sustavu. Kod hibrida $\mathrm{H} 5$ zabilježen je niži prinos zrna pri sjetvi u trake, za $0,59 \%$. Slično navedenome potvrđuju i istraživanja autora Novaceka i sur. (2013.) i Haegelea i sur. (2014.).

Tablica 7. Sklopovi biljaka kukuruza, masa zrna po klipu i ukupni urod zrna u 2018. godini sa standardnom sjetvom i sjetvom u trake

Table 7. Set of plants, grain weight per cob and grain yield in 2018 obtained with standard and twin row sowing

\begin{tabular}{|c|c|c|c|c|c|c|c|}
\hline \multirow{3}{*}{$\begin{array}{l}\text { Hibridi } \\
\text { Hybrid }\end{array}$} & \multicolumn{7}{|c|}{ Vegetacijska 2018. godina / Vegetation of 2018} \\
\hline & \multicolumn{2}{|c|}{ 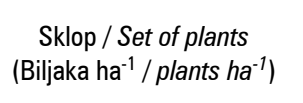 } & \multicolumn{2}{|c|}{$\begin{array}{l}\text { Masa zrna po klipu } \\
\text { Mass of grain per cob } \\
\left(\mathrm{g} \mathrm{klip}^{-1} / \mathrm{g} \mathrm{cob}^{-1}\right)\end{array}$} & \multicolumn{2}{|c|}{$\begin{array}{l}\text { Prinos zrna } \\
\text { Grain yield } \\
\left(\mathrm{kg} \mathrm{ha}^{-1}\right)\end{array}$} & \multirow{2}{*}{$\begin{array}{c}\text { Otklon uroda } \\
\text { Yield deviation } \\
(\%)\end{array}$} \\
\hline & $S T$ & $T R$ & $S T$ & $T R$ & $S T$ & $T R$ & \\
\hline$H 1$ & 65143 & $64255^{\text {n.s. }}$ & 188,95 & $203,54^{*}$ & 12296 & $13087^{\text {n.s. }}$ & 6,04 \\
\hline H2 & 63368 & $65320^{\text {n.s. }}$ & 194,92 & $211,85^{*}$ & 12335 & $13843^{*}$ & 10,89 \\
\hline H3 & 64255 & $63900^{\text {n.s. }}$ & 191,24 & $213,19^{*}$ & 12273 & $13630^{*}$ & 9,95 \\
\hline H4 & 66208 & $66598^{\text {n.s. }}$ & 188,04 & $211,74^{*}$ & 12448 & $14102^{*}$ & 11,72 \\
\hline H5 & 65675 & $65320^{\text {n.s. }}$ & 215,03 & $215,07^{\text {n.s. }}$ & 14133 & $14050^{\text {n.s. }}$ & $-0,59$ \\
\hline
\end{tabular}

ST - standardna sjetva / standard sowing; TR - sjetva u trake; udvojene redove / twin row sowing

Zbirni podatci prikazani su u Grafikonu 3, u kojem je vidljivo da je hibrid $H 2$, u usporedbi s ostalim hibridima, najbolje reagirao na tretmane sjetve u trake, $\mathrm{s}$ prosječnim prinosom većim za čak $10,64 \%$, što je također statistički signifikantno u odnosu na standardni sustav sjetve. Idući po pozitivnoj reakciji na različiti raspored biljaka, u prostoru sa sjetvom u trake su hibridi $F A O$ grupe $400, H 3$ i $H 4$, s 8,8 i 7,57\% većim prinosom pri sjetvi u trake, što je također statistički značajno u odnosu na standardnu sjetvu. Ova tvrdnja je vrlo zanimljiva za široku praksu proizvodnje kukuruza, jer su $F A O$ grupe 300 i 400 najzastupljenije u strukturi sjetve u ovome dijelu Europe, a kao takve najbolje toleriraju promjene vremenskih obrazaca (Jug i sur., 2018.). Hibrid $H 1$ je također zabilježio signifikantno povećanje prinosa od $6,04 \%$ pri sjetvi u trake. Najslabiju reakciju na promjenu sustava sjetve imao je hibrid $H 5$, kod kojega je povećanje uroda bilo nesignifikantnih 1,55\%. Razlog slabe reakcije na različit prostorni raspored biljaka pri sjetvi jest u njegovoj namjeni budući da je ovo hibrid namijenjen silaži, s bujnom lisnom masom (KWS, 2016.), kako je sugerirano u istraživanjima Novaceka i sur. (2013.) te istraživanjima gustoće sklopa više hibrida kukuruza (Franić i sur., 2015.). 


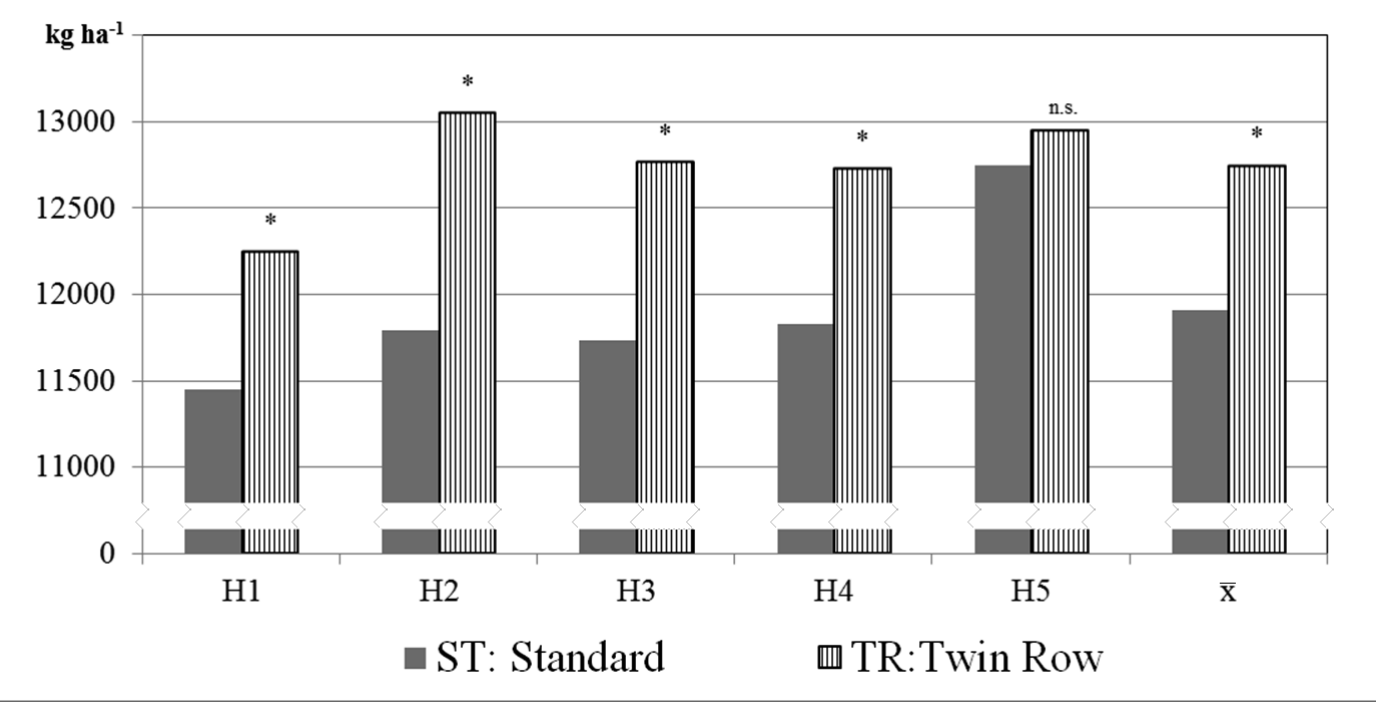

ST - standardna sjetva / standard sowing; TR - sjetva u trake; udvojene redove / twin row sowing

* - signifikantana razlika za $\mathrm{P}<0,05$ / significant difference at $P<0.05$; n.s. - nije signifikantno / nonsignificant

Grafikon 3. Ukupni urod zrna kukuruza za razdoblje 2016.-2018. sa standardnom sjetvom i sjetvom u trake Graph 3. Total maize grain yield in period of 2016-2018 obtained with standard and twin row sowing

\section{ZAKLJUČAK}

Sjetvom hibrida kukuruza različitih grupa dozrijevanja u dva sustava (standardna sjetva i sjetva u trake/ udvojene redove) tijekom trogodišnjega istraživanja može se zaključiti da je kod svih ispitivanih hibrida došlo do manjega povećanja prinosa zrna sa sjetvom u trake. Navedeno povećanje prinosa na trogodišnjoj razini statistički je značajno kod svih ispitivanih hibrida osim kod hibrida $H 5$. Hibrid $H 1$ sjetvom u udvojene redove ostvario je veći prinos za 3,77\% u 2016., 9,66\% u 2017. i $6,04 \%$ u 2019. godini. Sjetvom u udvojene redove hibrid $\mathrm{H} 2$ ostvario je povećanje prinosa od $10,97 \%$ u 2016., $6,46 \%$ u 2017. i 10,89\% u 2018. godini. Kod hibrida $\mathrm{H} 3$ sjetva u udvojene redove ostvarila je veći prinos zrna za 9,93\% u 2016., 3,45\% u 2017. i 9,95\% u 2018. godini. Hibrid $\mathrm{H} 4$ u 2017. godini ostvario je manji prinos sa sjetvom u trake, za $0,31 \% \mathrm{~s}$ obzirom na standardnu sjetvu. U 2016. i 2018. godini veći prinos ostvarila je sjetva u trake, za $8,06 \%$ i $11,72 \%$. Hibrid H5 ostvario je najniže postotne razlike ovisno o sustavu sjetve, a posebno u 2018. godini, pri čemu je ostvario manji prinos za $0,59 \%$. Na osnovi dobivenih rezultata, za većinu hibrida u grupama dozrijevanja $F A O 300$ do $F A O 400$, a koji se uzgajaju za zrno, može se preporučiti način sjetve u udvojene redove u danim agroekološkim uvjetima. Nadalje, iako je navedeno povećanje prinosa zrna u većini slučaja tijekom ovoga istraživanja potvrđeno sa statističkom značajnošću, potrebno je nastaviti komparacijska istraživanja s hibridima svih namjena i više različitih sjemenskih kuća.

\section{LITERATURA}

1. Balkcom, K. S., Satterwhite, J. L., Arriaga, F. J., Price, A. J. \& Van Santen, E. (2011). Conventional and glyphosa- te-resistant maize yields across plant densities in single and twin-row configurations. Field Crops Research, 120(3), 330-337.

https://doi.org/10.1016/j.fcr.2010.10.013

2. Banaj, A., Šumanovac, L., Hefer, G., Tadić, V., \& Banaj, Đ. (2017). Yield of corn grain by sowing in twin rows with MaterMacc-2 planter. In Proceedings of the 45th International Symposium on Agricultural Engineering, Actual Tasks on Agricultural Engineering, 21-24 February 2017, Opatija, Croatia (pp. 141-152). University of Zagreb, Faculty of Agriculture.

3. Banaj, A., Kurkutović, L., Banaj, Đ., \& Menđušić, I. (2017). Application of MaterMacc Twin row-2 seeder in corn sowing. In $10^{\text {th }}$ International Scientific/Professional Conference, Agriculture in Nature and Environment Protection, 5-7 June 2017, Vukovar, Croatia (pp. 180186). Croatian Soil Tillage Research Organization.

4. Banaj, A., Banaj, Đ., Dundović, D., Tadić, V. \& Lovrić, Ž. (2018a). Twin row technology maize sowing on family farm Vračić. $11^{\text {th }}$ International Scientific/Professional conference: Agriculture in nature and environment protection, 318-322.

5. Banaj, A., Banaj, Đ., Petrović, D., Knežević, D. \& Tadić, V. (2018b). Utjecaj sustava sjetve na prinos zrna kukuruza. Agronomski glasnik, 80(1), 35-48. https://doi.org/10.33128/ag.80.1.3

6. Banaj A., Banaj, Đ., Tadić, V., Petrović, D. \& Duvnjak, V. (2019). Rezultati sjetve kukuruza sijačicom Matermacc Twin Row-2 na pokušalištu Tenja. Proceedings of the $47^{\text {th }}$ International Symposium on Agricultural Engineering: Actual Tasks on Agricultural Engineering, 89-95.

7. Banaj, Đ., Banaj, A., Jurković, D., Tadić, V., Petrović, D. \& Lovrić, Ž. (2018). Sjetva kukuruza sijačicom MaterMacc Twin Row-2 na OPG-u Jasna Puhar. $11^{\text {th }}$ International Scientific/Professional conference: Agriculture in Nature and Environment Protection, 323-327. 
8. Blandino, M., Amedeo, R. \& Giulio, T. (2013). Aumentare la produttivitŕ del mais con alti investimenti e file binate. Un test in dodici localití vocate conferma la validitŕ delle nuove agrotecniche. Terra e Vita, Tecnica e Tecnologia, 7.

9. Elmore, R. W. \& Abendroth, L. J. (2007). Row spacing alternatives in corn. Proceedings of the Indiana CCA Conference, 20.

10. Franić, M., Mazur, M., Volenik, M., Brkić, J., Brkić, A. \& Šimić, D. (2015). Effect of plant density on agronomic traits and photosynthetic performance in the maize IBM population. Poljoprivreda, 21(2), 36-40. https://doi.org/10.18047/poljo.21.2.6

11. García F. J. R., Garasa, A. B. \& Cortés, M. V. (2014). Resultados productivos de un maíz sembrado con la máquina Monosem Twin-Row Sync-Row. Revista Vida Rural, 1.

12. Gutiérrez, L. M., \& Acosta, J. M. (2014). Resultados de la red de ensayos de variedades de maíz y girasol en Aragón. Dirección General de Alimentación y Fomento Agroalimentario, Servicio de Recursos Agrícolas, 253.

13. Haegele, J. W., Becker, R. J., Henninger, A. S. \& Below, F. E. (2014). Row arrangement, phosphorus fertility, and hybrid contributions to managing increased plant density of maize. Agronomy Journal, 106(5), 1838-1846. https://doi.org/10.2134/agronj2013.0382

14. Jocsak, A. (2014). Twin row: Better land use in twin row space with higher yields. https://mezohir.hu/index.php/ 12.12.2014.

15. Jug, D., Jug, I., Brozović, B., Vukadinović, V., Stipešević, B. \& Đurđević, B. (2018). The role of conservation agriculture in mitigation and adaptation to climate change. Poljoprivreda, 24(1), 35-44. https://doi.org/10.18047/poljo.24.1.5
16. Jurković, D., Kajić, N., Banaj, A., Tadić, V., Banaj, Đ. \& Jović, J. (2017). Twin row technology maize sowing. Proceedings of the $8^{\text {th }}$ International Agricultural Symposium: Agrosym 2017., 62-66.

17. Jurković, D., Kajić, N, Banaj, A. \& Banaj, Đ. (2018). Utjecaj načina sjetve na prinos zrna kukuruza. $53^{\text {rd }}$ Croatian and $13^{\text {th }}$ International Symposium on Agriculture, 299-303.

18. Küper, J. M. (2014). Das Maissägerät von morgen - Trends in der Einzelkornsaat. Top Agrar, Landwirthschaftsverlag Münster, 24.01.2014.

19. KWS (2016). Konsens - zeleni div. https://www.kws. $\mathrm{hr} / \mathrm{aw} /$ Proizvodi/kukuruz/KONSENS-NOVO/ fxly/, 24.01.2014.

20. Nelson, K. A. \& Smoot, R. L. (2009). Twin and SingleRow Corn Production in Northeast Missouri. Crop Management, 8.

https://doi.org/10.1094/CM-2009-0130-01-RS

21. Novacek, M.J. (2011). Twin-row production and optimal plant population for modern maize hybrids. Major thesis. M.S. thesis. Univ. of Nebraska, Lincoln.

22. Robles, M., Ciampitti, I. A. \& Vyn, T. J. (2012). Responses of Maize Hybrids to Twin - Row Spatial Arrangement at Multiple Plant Densities. Agronomy Journal 104, 17471756. https://doi:10.2134/agronj2012.0231

23. Roth, G. S., Harkcom, S. H. \& Antle, M. (2002) Comparison of Twin Row and Single Row No-Till Corn Planted for Grain. Penn State Extension, 17.10.2012.

24. Tadić, V., Banaj, A., Banaj, Đ., Petrović, D. \& Knežević, D. (2017). Twin row technology for maize seeding. The Third International Symposium on Agricultural Engineering, 69-74.

\section{IMPACT OF SOWING SYSTEM ON MAIZE GRAIN YIELD OF DIFFERENT FAO GROUPS}

\section{SUMMARY}

In this paper, the results of maize grain yield $\left(\mathrm{kg} \mathrm{ha}^{-1}\right)$ sown in standard and twin row technology are shown. The research has been conducted at the experimental field of Faculty of Agrobiotechnical Sciences, near location of Tenja $\left(45^{\circ} 31^{\prime} 1.83^{\prime \prime} N\right.$ N 18 $46^{\prime} 3.5^{\prime \prime}$ E) in the period 2016-2018. Maize hybrids H1 = FAO 290, H2 = $F A O 380, H 3=F A O 410, H 4=F A O 450$ and H5 = FAO 590 were sown using standard sowing (row spacing at $70 \mathrm{~cm}$ ) and twin row sowing (22 cm spacing between double rows). In standard sowing, hybrid $\mathrm{H} 1$ had the highest grain yield of 11,450 $\mathrm{kg} \mathrm{ha}^{-1}$, whereas in twin row sowing it had 12,243 $\mathrm{kg} \mathrm{ha}^{-1}$, which was higher by 3.77-9.66\% than the standard, depending on the cultivation year. Hybrid $\mathrm{H} 2$ in twin row sowing had grain yield 6.46-10.97\% greater than standard sowing. Hybrid $\mathrm{H3}$ in standard sowing had average grain yield of 11,731 $\mathrm{kg} \mathrm{ha}^{-1}$, whereas in twin row sowing, it was $12,763 \mathrm{~kg} \mathrm{ha}^{-1}$ (greater by 3.45-9.95\%). The highest grain yield difference between sowing technologies has been observed at $\mathrm{H} 4$ hybrid, with $11.72 \%$ greater yield at twin row sowing. At hybrid H5, the smallest differences were observed between sowing technologies, so in 2018, twin row sowing produced a lower yield by $0.59 \%$ relative to standard sowing.

Keywords: maize, standard sowing, twin row sowing, twin row seeder, grain yield

(Received on September 17, 2019; accepted on November 20, 2019 - Primljeno 17. rujna 2019.; prihvaćeno 20. studenoga 2019.) 